\title{
347.251
}

\section{A "Gewere" - Um Instituto do Antigo Direito Germânico.}

\author{
José Carlos Moreira Alves \\ Professor Catedrático de Direito Civil da
Faculdade de Direito da Universidade de \\ Faculdade de Direito da
São Paulo.
}

\begin{abstract}
SUMÁrio: 1. A importância da Gewere para o conhecimento da posse no direito moderno. 2. O conceito da Gewere. 3. Espécies de Gewere. 4. Aquisição e perda da Gewere. 5. Os três efeitos da Gewere.
\end{abstract}

1. A importância da Gewere para o conhecimento da posse no direito moderno. - É inegável a influência do Bürgerliches Gesetzbuch (B.G.B.) sôbre várias legislações civis modernas. Entre elas, encontra-se o Código Civil Brasileiro, que, com relação à posse - entre outras matérias -, seguiu, em pontos de importância capital, a codificação germânica. Como exemplo disso, basta salientar que o artigo 486 do Código Civil Brasileiro, que introduziu, em nosso direito, a distinção fundamental entre posse direta e indireta, nada mais é do que reprodução do $\S 868$ do B.G.B., como se demonstra com o simples confronto entre os dois textos:

“Artigo 486. - Quando por fôrça de obrigação, ou direito, em certos casos como o do usufrutuário, do credor pignoratício, do locatário, se exerce temporàriamente a posse direta, não anula esta às pessoas, de quem êles a houveram, a posse indireta"; e 
“ 8 868. - Besitz jemand eine Sache als Niessbraucher, Pfandgläubiger, Pächter, Mieter, Verwahrer oder in einem ähnlichen Verhältnisse, vermöge dessen er einem anderen gegenüber auf Zeit zum Besitze berechtigt oder verpflichtet ist, so ist auch der andere Besitzer (mittelbarer Besitz)". (Se alguém possuir uma coisa como usufrutuário, credor pignoratício, arrendatário, locatário, depositário, ou por uma relação análoga, em virtude da qual, em face de outrem, tenha direito ou esteja obrigado a possuir temporàriamente, é êste também possuidor (posse mediata).

Ora, dois foram os projetos que se sucederam na fase de elaboração do Bürgerliches Gesetzbuch: o primeiro, de 1888', que, segundo VoN $\mathrm{THUR}^{2}$, foi acolhido desfavoràvelmente, porque, além de demasiado teórico, se vinculava estreitamente ao direito romano ${ }^{3}$ e não atendia às necessidades da vida moderna; e o segundo, de $1895^{4}$, que, com

1. Entwurf eines bürgerlichen Gesetzbuches für das Deutsche Reich. Erste Lesung. Amtliche Ausgabe, Berlin und Leipzig, Verlag von J. Guttentag, 1888 (há tradução francesa de RAOUL DE LA GrAsSERIE, Projet de Code Civil Allemand, Paris, A. Durand et Pedone, Lauriel, Editeurs, 1893).

2. Bürgerliches Recht - Allgemeiner Teil (in Enzyklopädie der Rechts-und Staatswissenschaft, herausgegeben von Kohlrausch, Kaskel, Spiethoff), Berlin, 1923, § 2, II, p. 2. Vide, também, DernburG, Das bürgerliche Recht des Deutschen Reichs und Preussens, erster Band,

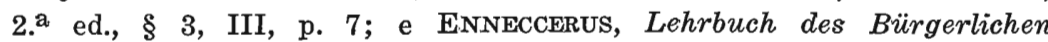
Rechts, erster Band (erster Halbband), 14. ${ }^{\mathrm{a}}$ ed. (neubearbeitete Auflage von NIPPERDEY), § 12, III, p. 33.

3. Sua vinculação com os pandectistas era tão grande que BÄHR (apud BEKKER, System und Sprache des Entwurfes eines Bürgerlichen Gesetzbuches für das Deutsche Reich, p. 85, nota 29) chamou o primeiro projeto de "den kleinen Windscheid" (o pequeno Windscheid).

4. Entwurf eines Bürgerlichen Gesetzbuchs für das Deutsche Reich. Zweite Lesung. Auf amtliche Veranlassung. Berlin, J. Guttentag, Verlags - buchhandlung, 1895. 
alterações, se transformou no B.G.B., e no qual se introduziram concepções do antigo direito germânico ${ }^{5}$.

Em virtude disso, enquanto no primeiro projeto, em matéria de posse, se seguiu orientação eminentemente romanística, no Bürgerliches Gesetzbuch - em decorrência das diretrizes que presidiram aos trabalhos da, Comissão que elaborou o segundo projeto - observa-se, como salienta $G_{\mathrm{IERKE}}{ }^{6}$, a existência de fortes vestígios de influência germânica, razão por que, para bem se compreender o instituto da posse no B.G.B. (e, conseqüentemente, nos Cindigos que, a propósito, nele se calcaram, como o Código Civil Brasileiro) ${ }^{7}$, é indispensável que se tenham noções da Gewere, que, no antigo direito germânico, é o instituto que se encontra, sob certos aspectos, em posição semelhante à da possessio na legislação romana.

5. A propósito, vide Cosack, Lehrbuch des Deutschen bürgerlichen Rechts, erster Band, § 7, 3, in fine, p. 28.

6. Deutsches Privatrecht, Zweiter Band (Sachenrecht), Leipzig, 1905, § 114, p. 211, onde - embora reconhecendo (o que, aliás, já afirmara em Die Bedeutung der Fahrnisbesitz für streitiger Recht nach dem Bürgerlichen Gesetzbuch für das Deutsche Reich, Jena, 1897, p. 1 e seg.) que o conceito de posse no B.G.B. é romano - acentua:

"Das heutige Besitzrecht setz somit zugleich das römische Recht der possessio und das germanische Recht der Gewere - fort".

CosAcK (Lehrbuch des Deutschen bürgerlichen Rechts, II, 1. ${ }^{\mathrm{a}}$ ed., $\S 185$, p. 62), no entanto, vai além, e pretende que mesmo o conceito de posse no B.G.B. está mais próximo da Gewere do que da possessio romana.

7. Observa Gondim Neto, em Posse Indireta, p. 5 e seg.:

"Não tenho, devo logo dizer, nenhuma admiração pelo trabalho científico de nosso Codificador em matéria de posse, onde, restringindo-me ao tema escolhido, e deixando de parte, assim, outras grosseiras incongruências, só descubro a inconveniente $e$ incompleta trasladação de doutrinas arcáicas corporificadas no Código Germânico" (os grifos são nossos). 
No B.G.B., portanto, com relação à posse, acham-se, lado a lado, principios derivados do direito romano e do direito germânico, havendo - como acentua H. Mitreis ${ }^{8}-$ preponderância dêstes sôbre aquêles. E, ainda consoante H. MrTters ${ }^{9}$, as concepções germânicas foram acolhidas no B.G.B. principalmente nestes pontos:

a) a posse, no direito alemão moderno, é reconhecida como um direito, ou, mais precisamente, como "direito real provisório" (vorläufiges $S a$ chenrecht);

b) reconhece-se a posse múltipla (mediata e imediata);

c) estabelece-se a posse do herdeiro: êste adquire, automàticamente, independente de imissão efetiva, a posse da herança no momento em que falece o de cuitus; $\mathrm{e}$

d) embora, quanto à proteção possessória, se concedam os interditos possessórios que vêm do direito romano, e, portanto, se exclua, em geral, a alegação de posse melhor, é isso admitido nas hipóteses previstas no $\S 1.007$ do B.G.B., onde se introduziu, no direito alemão moderno, graças ao segundo projeto, a ação que Salleiles 10 denomina "ação de reivindicação de posse", e que Pontes de Miranda ${ }^{11}$ prefere designar com a expressão "ação vindicatória de posse"12.

8. Deutsches Privatrecht, $3 .^{\mathrm{a}}$ ed. (neubearbeitet von HEINZ LIEBERICH), München und Berlin, 1959, p. 76.

9. Ob. cit, p. 76 e seg.

10. De la possession des meubles, Paris, 1907, p. 273 e seg.

11. Tratado de Direito Privado, X, Rio de Janeiro, 1955, § 1.133, p. 388 e seg.

12. Segundo Pontes de Miranda (e sua opinião se encontra não apenas no Tratado de Direito Privado, X, § 1133 e seg., p. 388 e seg., 
O presente artigo tem por finalidade exclusiva divulgar, entre nossos civilistas, as noções fundamentais sôbre a Gewere. Nele procuraremos - e, pelo que sabemos, é a primeira vez que, sistemàticamente, se trata da Gewere, no Brasil $^{13}$ - dar uma idéia geral do que existe, na doutrina germânica, a respeito da Gewere, que foi no direito miedieval, na expressão de H. MitTEIS" ${ }^{14}$, "o conceito nuclear do direito das coisas alemão" (der Zentralbegriff des deutschen Sachenrechts).

mas também em obras anteriores - assim, nas Fontes e Evolução do Direito Civil Brasileiro, n. ${ }^{\circ} 117$, p. 221; e no Manual do Código Civil Brasileiro, XVI, 1, p. 270 e seg.), o Código Civil Brasileiro, no artigo 521, introduziu, em nosso direito, ação vindicatória da posse correspondente à do $\S 1007$ do B.G.B. A nosso ver, porém, é falsa a tese de Pontes DE Miranda, como procuramos demonstrar, sumàriamente, no verbete Perda da posse, publicado no Repertório Enciclopédico do Direito Brasileiro, XXXVII, Rio de Janeiro, sem data, p. 13.

13. Com efeito, em nosso país, mesmo os autores mais fortemente influenciados pelos civilistas aleinães - como EdUARDo EsPínola e PONTES DE MIRANDA - apenas aludem, de passagem, à Gewere, quando se ocupam da posse (vide, a propósito, EdUARDo EsPínola, Posse Propriedade - Co-propriedade ou Condominio - Direitos autorais, Rio de Janeiro, 1956, § 24, p. 42 e seg.; e Pontes DE Miranda, ob. cit., X, passim).

Também nos autores portuguêses que se referem à Gevere, no estudo do direito visigótico ou do antigo direito português, não se encontra exposição mais ampla sôbre êsse instituto do antigo direito

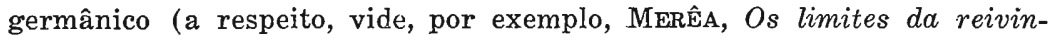
dicação mobiliária no direito medieval, in Estudos de Direito Hispânico Medieval, I, Coimbra, 1958, p. 1 e seg.; CABRAL DE MonCADA, $A$ "posse de ano e dia" nos costumes municipais portuguêses, in Estudos de História do Direito, I, Coimbra, 1948, p. 240 e seg.; Marnoco E SouzA, História das Instituições do Direito Romano, Peninsular e Português, Coimbra, 1910, 3. ${ }^{a}$ ed., $\S 203$ e 210, p. 456 e seg., e 472 , respectivamente).

14. Ob. cit., p. 73. No mesmo sentido, HÜBNER, Grundzüge des Deutschen Privatrechts, $3 .^{\mathrm{a}}$ ed., $\S 28$, p. 163 :

"Alle dinglichen Rechte, sowohl das Eigentum wie die an Fahrnis, erschienen in der äusseren Form, in dem Kleide 
Para que se saiba da dificuldade que há nessa exposição - o que, òbviamente, serve de excusa a algum lapso -, basta salientar que um dos mais célebres historiadores do direito germânico - Brunner —, ao se ocupar da Gewere, em seu trabalho Geschichte und Quellen des Deutsches Rechts, que se encontra na quarta edição da Enzyklopädie der Rechtswissenschaft publicada por HolTzENDoRfF, não hesitou em salientar que mesmo o significado jurídico da Gewere ainda era questão não solucionada pela literatura germanística $^{15}$. Isso, em 1882. Alguns anos mais tarde, em 1894 (quando já se achavam divulgadas várias das mais importantes obras que se escreveram sôbre a Gewere), outro jurisconsulto de nomeada - FrankeN ${ }^{16}$ - afirmou que não se podia indicar, com precisão, a influência das

einer sogenannten "Gewere". Daher war in der Tat die Gewere die "Grundlage" des mittelalterlichen Sachenrechts".

As afirmações de MITTeIs e de HÜBiNER demonstram que a doutrina moderna volta a dar à Gewere a mesma importância que lhe atribuia ALBREGHT, em contraposição à tendência doutrinária que levou SтоввE (Handbuch des Deutschen Privatrechts, 2. ${ }^{\mathrm{a}}$ ed., Berlin, 1883. p. 11, nota 1) à seguinte observação:

"Die neueren Arbeiten haben gezeigt, dass die Bedeutung der Gewere für das Alte Sachenrecht oft überschätz worden und dass Albrecht's Auffassung, die Gewere sei die Grundlage des deutschen Sachenrechts, unhaltbar ist"

15. Leipzig, 1882, p. 248. Na 7. ${ }^{\mathrm{a}}$ ed. da Enciclopédia de HoltzeNDORFF, publicada por KOHLER, BRUNNER, a cujo cargo continuou a redação da Geschichte und System des deutschen und römischen Rechts, ao invés de manter o que havia escrito na $4 .^{\mathrm{a}}$ ed., reformulou totalmente a passagem relativa à Gewere, reproduzindo o resumo didático (e, portanto, sem caráter polêmico) que se encontra em sua obra Grundzüger der dëutschen Rechtsgeschichte (de cuja oitava edição - editada por ScHWERIN - há tradução espanhola, sob o título Historia del Derecho Germánico, publicada, em 1936, pelo Editorial Labor, S.A.).

16. Lehrbuch des Deutschen Privatrechts, Leipzig, 1894, § 21, p. 174 e 175 . 
concepções do antigo direito germânico sôbre o direito moderno, porque, apesar das numerosas pesquisas históricas, ainda faltavam resultados incontroversos sôbre a Gewere. E, com efeito, nessa época, com relação à Gewere em geral, podia-se dizer o que Bruns, em Die Besitzklagen des römischen und heutigen Rechts ${ }^{17}$, observava, ao acentuar que a natureza da ação mobiliária germânica ainda não estava esclarecida:

"Jede neue Bearbeitung bringt eine neue Ansicht" (Cada nova revisão traz uma nova opinião);

ou o que, mais tarde, em 1911, Schultze, no artigo Die Bedeutung des Zuges auf den Gewähren in Anefangsverfahren, publicado no Festschrift Otto Gierke zum siebzigsten Geburtstag ${ }^{18}$, escrevia sôbre a Fahrnisverfolgung:

"Die Fahrnisverfongung des germanischen Rechts, so oft sie behandelt wurde, ist immer noch Gegenstand lebhafter Diskussion" (A seqüela mobiliária do direito germânico, tantas vêzes tratada, ainda é sempre objeto de viva discussão).

É por tudo isso que não devem causar estranheza as palavras prudentes de Bourcart, ao ocupar-se da Gewere no Etude historique et pratique sur les actions possessoires ${ }^{19}$ :

“Je n'ai pas la prétension de donner un exposé irreprochable de cette institution encore obscure pour les jurisconsultes allemands eux-mêmes. Je crois cependant que les quelques idées, que je vais émettre, et qui sont en général le résumé des opinions d'auteurs très considerables (voir n. 1)

17. Weimar, 1874, § 21, p. 229.

18. Weimar, 1911, p. 759.

19. Paris, $1880, \S 66$, p. 156 , nota 2. 
offrent, sinon une certitude absolue, tout au moins une grande vraissemblance".

Não seria preciso dizer que fazemos nossas essas palavras, embora atualmente - graças, sobretudo, aos trabalhos de Huber $^{20}$ e de Gierke ${ }^{21}$ - já se tenha afastado, em vários pontos, a penumbra que envolvia a Gewere ${ }^{22}$.

2. O conceito controvertido de Gewere ${ }^{23}$. - Nas fontes medievais do direito germânico, encontra-se a palavra Gewere - com que se traduzem os vocábulos uestitura e inuestitura dos textos jurídicos medievais escritos em latim $^{24}$ — empregada em diferentes acepções.

20. Die Bedeutung der Gewere im Deutschen Sachenrecht (Festschrift im Namen und Auftrag der Universität Bern), 1894.

21. Die Bedeutung der Fahrnisbesitz für streitiger Recht nach dem Bürgerlichen Gesetzbuch für das Deutsche Reich, Jena, 1897; e Deutsche Privatrecht, II (Sachenrecht), Leipzig, 1905 (§ 113, p. 187 e seg.).

22. Escreve, a propósito, HÜBNER (Grundzüge des Deutschen Privatrechts, $3 .^{\mathrm{a}}$ ed., Leipzig, 1919, § 28, p. 163) :

"Seit ALbRechts berühmter Monographie stand das Problem der Gewere im Mittelpunkt der Forschungen über die Geschichte des deutschen Privatrechts. Bahnbrechend wirkten nach ihm zumal die Schriften von LABAND und HEusLeR. Aber erst die neuesten Untersuchungen von HuBER, denen GieRKe, HERBeRT MEYeR, Alfred SChultZe bei tragen, haben diejenige Klärung gebracht, die als endgültige Lösung wenigsten der hauptsächliehsten Rätsel angesehen werden kann".

23. É muito vasta a literatura germânica sôbre a Gewere. O leitor encontrará ampla informação bibliográfica em STOBBE-LEHMANN, Handbuch des Deutschen Privatrechts, 3. ${ }^{\mathrm{a}}$ ed., Zweiter Band (Erster Haldband), Berlin, 1896, § 85, p. 190 e seg., nota 1; e em GIERKE, Deutsches Privatrecht, Zweiter Band (Sachenrecht), Leipzig, 1905, $\S 113$, p. 187 , nota 1 . 
Ao que parece - e nesse sentido se manifestam, entre outros, Brunner ${ }^{25}$, StoBbe ${ }^{26}$, HeIlfron ${ }^{27}$ e $\mathrm{HüBNER}^{28}$-, primitivamente Gewere designava o ato pelo qual se transferia juridicamente um imóvel, e no qual a pessoa que até então exercera a senhoria sôbre êle declarava que a renunciava (Auflassung). Posteriormente, Gewere passou a indicar, também, a relação de senhoria entre pessoa e coisa, quer essa relação tivesse por objeto coisa móvel ou imóvel, quer ela surgisse por modo de aquisição derivada ou originária. Enfim, Gewere - como salientam STOBBE $^{29}$ e HeILfron ${ }^{30}-$

24. Para provas da identidade entre Gewere e uestitura ou inuestitura, vide STовве, Handbuch des Deutschen Privatrechts, Zweiter Band, 2. ${ }^{a}$ ed., Berlin, 1883, § 72, p. 11, nota 2.

25. Quellen und Geschichte des deuteschen Rechts, in Enzyklopädie der Rechtswissenschaft de HoLTZENDORFF (7. ${ }^{\mathrm{a}}$ ed., publicada por KOHLER), Firster Band, § 46, p. 133.

26. Handbuch des Deutschen Privatrechts, Zweiter Band, Berlin, 1883 (2. ${ }^{\mathrm{a}}$ ed.), § 72, p. 11 e seg.

27 Deutsche Rechtsgeschichte, $7 .^{\mathrm{a}}$ ed., Berlin, 1908, § 64, p. 500.

28. Grundzüge des Deutschen Privatrechts, $3 .^{\text {a }}$ ed., Leipzig, 1919, $\S 28$, p. 164.

29. Handbuch des Deutschen Privatrechts, Zweiter Band, Berlin, 1883 (2. ${ }^{\mathrm{a}}$ ed.), § 72, p. 12.

Note-se, ainda, que STаввE, ob. cit., II, § 72, p. 12 e seg., nota 7.a - e com êle, contra a opinião de LABA'ND e de HEUSLER, concorda Meischeider, Besitz und Besitzschutz, Berlin, 1876, §50, p. 247 e seg. - defende a tese de que, nas fontes medievais, se encontra a palavra Genvere para indicar, também, o direito à posse (das Recht zu besitzen).

LehmanN, porém, na $3 .^{\mathbf{a}}$ ed, da obra de StobBe (Berlin, 1896, $\S 85$, p. 195), que antes é uma reelaboração do que pròpriamente uma reedição, salienta (e nesse sentido se manifesta a doutrina mais recente) :

"Dagegen bedeutet Gewere nicht: das Recht auf den Nutzungsbesitz, also das Recht auf die Gewere"

$\mathrm{E}$, em nota ( . $^{\circ} 16$, p. 196), acrescenta que as citações de fontes feitas por SToBbe nada provam em favor de sua tese.

30. Deutsche Rechtsgeschichte, $7 .^{\mathrm{a}}$ ed., Berlin, 1908, § 64, p. 500. 
traduz o objeto (Besitzum, Haus und Hof) sôbre que incide essa senhoria.

Iremos, no presente estudo, ocupar-nos apenas com a segunda dessas acepções - a Gewere como relação de senhoria entre uma pessoa e uma coisa.

A Gewere (a que as fontes jurídicas francêsas aludem com o têrmo saisine; as italianas, com a expressão tenuta; e as inglêsas, com a palavra seisin) ${ }^{31}$ é o instituto que, no direito germânico medieval, corresponde à possessio, que só foi introduzida no direito alemão com a recepção, na Alemanha, do direito romano, o que apenas ocorreu no século XVI32.

Mas - note-se - correspondência não significa igualdade: a Gewere, se apresenta pontos de contacto com a possessio, dela se afasta em outros aspectos. Basta atentar para o fato de que, enquanto o direito romano distinguiu, nìtidamente, as três posições em que decorre para uma pessoa poder sôbre uma coisa (propriedade, posse e detenção), o direito germânico medieval desconheceu, quanto às coisas móveis, a diferença entre posse e detenção, e -

31. A palavra Gewere (a propósito, vide, entre outros, GIERKE, Deutsches Privatrecht, II, § 113, p. 188, nota 3; SтоввE, Handbuch des Deutschen Privatrechts, 2. ${ }^{\mathrm{a}}$ ed., $\S 72$, p. 12, nota 3; e SCHULte, Lehrbuch der deutschen Reichs - und Rechtsgeschichte, $4 .^{\text {a }}$ ed., § 146, nota 1, p. 461 e seg.) deriva de wern (do gótico vasjan, que significa vestir), tomada no sentido de vestire (além dêsse significado, wern é empregada em dois outros: no de prohibere, defendere; e no de praestare - de onde resultam, respectivamente, os vocábulos Gewehr e Gewähr, que não devem ser confundidos com a Gewere).

32. Vide, a propósito, Baron, Pandekten, 6. ${ }^{\text {a }}$ ed., Leipzig, 1887, $\S 1$, p. 1 e seg. Sôbre a recepção do direito romano na Alemanha, consulte-se o amplo estudo de WIEAcker, Historia del Derecho Privado de la Edad Moderna, trad. FERNÁNDEZ JARDON, Madrid, 1957, § 7 e seg., p. 89 e seg. 
embora a maioria dos germanistas entenda o contrário ${ }^{33}$ - há autores ${ }^{34}$ que chegam a negar que o direito germânico medieval tenha estabelecido distinção entre propriedade e posse (essas figuras estariam abrangidas na Gewere).

Divergem os juristas germânicos com relação ao conceito de Gewere. Tomando por ponto de partida a monografia clássica de AlbRecht (Die Gewere, als Grundlage des ältern deutschen Sachenrechts) ${ }^{35}$, vinda à luz em Königsberg, em 1828, distingue HEILFRON ${ }^{36}$, a respeito, três correntes de opinião, que se sucederam cronològicamente:

a) a defendida por Albrecint;

b) a representada por LABANd e Heusler; e

c) a encabeçada por Gierke e Huber.

A Gewere, segundo Albrecht, seria algo tão singular que os autores que procuram sintetizar-lhe o pensamento encontram dificuldade em fazê-lo. Assim, HuBER ${ }^{37}$ salienta que, para AlbReGht, a Gewere não era nem direito real,

33. Vide, por exemplo, Sтовве, Handbuch des Deutschen Privatrechts, $\Pi, 2 .^{\mathrm{a}}$ ed., Berlin, 1883, § 72, p. 10, que é categórico ao afirmar:

"Der Gegensatz zwischen dem Recht an einer Sache und dem Besitz der Sache, d. h. der Ausübung eines Rechts an ihr ist auch schon dem ältern deutschen Recht bekannt".

34. A propósito, vide GLASson, De la possession et des actions possessoires au Moyen-Age, in Nouvelle Revue Historique de Droit Français et Étranger, XIV (1890), p. 590 e seg.; MINGUIJoN, Historia del Derecho Espanol, I, p. 139 e seg.; BetrmMANN-HollWeg, Der Germanisch - romanische Civil - Prozess in Mittelalter, I (4. ${ }^{\circ}$ volume da obra Der Civilprozess des gemeinen Rechts in geschichtlichen Entwicklung), unveränderter Neudruck, 1959, § 8, p. 14.

35. Os autores são unânimes em reconhecer que o primeiro trabalho fundamental sôbre a Gewere foi o de AlBRECHT.

36. Deutsche. Rechtsgeschichte, 7.a ed., $\S 64$, p. 500 e seg.

37. Die Bedeutung der Gewere im Deutschen Sachenrecht, p, 6 
nem direito pessoal, mas apresentava, em tôdas as formas de sua manifestação, a mesma característica: a de ser o direito à representaçâo da coisa (das Recht zur Vertretung der Sache). Beseler ${ }^{38}$ acentua que Albrecht defendia a tese de que a Gewere era uma relação jurídica -- djversa da em que se encontrava o direito real - protegida por uma ação real. Já, consoante HeILfron ${ }^{39}$, Albrechit julgava que a Gewere era o direito à posse (Besitzrecht) de uma coisa, tutelado por uma ação real autônoma. Mais esclarecedor é Gerber ${ }^{40}$, segundo o qual AlbREcht entende que o direito alemão não conferia ação ao direito real, uma vez que o direito de ação - no caso, o fator formal da seqüela judiciária da coisa contra terceiro - era independente do direito real, e existia quando se preenchiam seus próprios pressupostos; êsse direito de ação (Klagerecht), independente do direito real, era a Gewere.

A tese de Albzecht, em suas próprias palavras, é esta:

"Suchen wir für den Begriff der Gewere, der in das Recht zur Vertretung der Sache gesetzt worden ist, einen ihm entsprechtenden, welcher ihn unserm heutigen Rechte näher bringt, so bietet sich ein solcher in dem Bregriffe der Dinglichkeit dar. Gewere ist dasjenige, was einem Verhältnisse der Person zur Sache (ich sage absichtlich nicht: einem Rechte an der Sache) dingliche Wirksamkeit, d. h. eine dingliche Klage, oder Sicherheit gegen die dingliche Klage eines Andern giebt; wem die Gewere fehlt, dessen Interesse kann nur noch persönliche, obligatorische Wirksamkeit haben" - "Se

38. System des gemeinen deutschen Privatrechts, erster Abtheilung, Berlin, 1885, § 78, p. 312, nota 9.

39. Deutsche Rechtsgeschichte, $7 .^{\mathrm{a}}$ ed., $\S 64$, p. 500 e seg.

40. System des Deutschen Privatrechts, 17. ${ }^{\text {a }}$ ed., Jena, 1891, $\S 72$, p. 117 , nota 4 . 
procurarmos para o conceito de Gewere, o qual foi colocado no direito à representação da coisa, um correspondente a êle que lhe traga mais perto do nosso direito atual, êsse conceito se apresenta no de realidade (Dinglichkeit). Gewere é aquilo que dá a uma relação de pessoa a coisa (eu não digo, intencionalmente: a um direito sôbre a coisa) eficácia real, isto é, uma ação real, ou proteção contra a ação real de terceiro; a quem falta a Gewere, seu interêsse pode ter sòmente eficácia pessoal, obrigatória"40a.

Contra a opinião de Albrecht manifestaram-se, posteriormente, Laband e Heusler, entendendo ambos que a Gewere, no direito germânico medieval, era - ̀̀ semelhança da possessio, no direito romano - o poder de fato de utilização e gôzo de uma coisa. Resumindo suas idéias expendidas, primeiramente, na monografia Die Gewere, publicada em 1872, acentua HeusLer, nas Institutionen des Deutschen Privatrechts ${ }^{41}$, que a Gewere não é pròpriamente úm direito, e, nas fontes germânicas, jamais é considerada como tal; ao contrário, é ela sempre apresentada como relação de senhoria de fato, como expressão de fato da dominação sôbre uma coisa. Mas - continua Heusler --, a Gevere com êsse conteúdo puramente de fato tem, no sistema jurídico germânico, posição determinada e firme como a possessio, no direito romano, porquanto uma senhoria que existe de fato é, sempre, uma fôrça que tôda ordẹ juridica tem que reconhecer e contar com ela.

Mais recentemente, GIERKE ${ }^{42}$ e HubER ${ }^{43}$ (êste, partindo da análise dos efeitos da Gewere para chegar à sua con-

40a. Die Gewere, neudruck der Ausgabe Königsberg 1828, Aalen, 1967, p. 125.

41. II, § 81, p. 20 e seg.

42. Deutsches Privatrecht, II (Sachenrecht), § 113, p. 187 e seg. 
ceituação) divergem das duas teses anteriores, e entendem, em síntese, que a Geurere nada mais é do que o elemento formal e, conseqüentemente, exterior do direito real ${ }^{44}$. Daí, afirmar Huber $^{45}$ que a Gewere se apresenta como a forma sob a qual o direito real é defendido, conquistado e transferido; por isso, não há direito real que não seja representável através de uma Gewere, mas, ao contrário, todo direito real é reconhecido no comércio jurídico sob a figura de uma Gewere.

Se, porém, analisarmos, nos pormenores, as teses defendidas por GIERKK e por HubER, veremos que elas - como bem observa SoKoLowsKi ${ }^{46}$ - não são rigorosamente coincidentes, pois, enquanto GIERKE ${ }^{47}$ acentua que a $\mathrm{Ge}$ were é a simples veste do direito real, $\mathrm{HUBER}^{48}-\mathrm{e}$, no mesmo sentido, Stobbe-LehmanN ${ }^{49}$ - salienta que ela é o conteúdo econômico do direito real.

43. Die Bedeutung der Gewere in Deutschen Sachenrecht.

44. Aludindo a essa divergência de correntes doutrinárias, acentua HÜBNER (Grundzüge des Deutschen Privatrechts, 3.a ed., § 28, p. 163) que sòmente as pesquisas de HUbER, GIERKE, MEYER e ScHUlTZE trouxeram esclarecimentos que podem ser tidos, pelo menos, como solução definitiva dos enigmas capitais da Gewere.

45. Die Bedeutung der Gewere im Deutschen Sachenrecht, p. 21 e seg.

46. Die Philosophie im Privatrecht, II (Der Besitz im klassischen Recht und dem deutschen bürgerlichen Gesetz), unveränder Neudruck, 1959, Aalen, p. 230 e 429 (notas 435 e 436).

47. Deutschen Privatrecht, II (Sachenrecht), § 113, p. 187 e seg.

48. Die Bedeutung der Gewere im deutschen Sachenrecht, p. 23. e seg.

49. Handbuch des Deutschen Privatrechts von Oтто Sтовве, neu bearbeitet von H. O. LeHMAN, II, $1,3 .^{a}$ ed., $\S 85$, n. ${ }^{\circ} 3$, p. 193 , onde se lê:

"Die Gewere ist der wirthschaftlich werthvolle Inhalt aller dinglichen Rechte". 
Por outro lado, segundo a doutrina mais moderna (que, nesse particular, segue $\mathrm{HUBER}^{50}$ ), para que haja a Gewere é preciso, por via de regra, que se preencham dois requisitos (que lembram - como salienta HüBNER $^{51}$ - os dois elementos constitutivos da possessio: o corpus e o animus) :

a) a senhoria de fato sôbre a coisa; e

b) a afirmação de que essa senhoria de fato corresponde a um direito real sôbre a coisa.

Dêsses dois requisitos, o primeiro - a senhoria de fato -, em alguns poucos casos (nas hipóteses em que se configura a ideelle Gewere - vide, adiante, o número 3), não ocorre, e, isso não obstante, há a Gewere. Em geral, no entanto, é necessário que haja a senhoria de fato sôbre a coisa, para que sôbre ela se tenha a Gewere. Mas essa senhoria de fato se apresenta de forma diversa, conforme o objeto da Gewere seja coisa móvel ou imóvel. Na Gewere sôbre coisa móvel, a senhoria de fato se traduz na detenção da coisa; na Gewere sôbre coisa imóvel, há senhoria de fato desde que exista utilização econômica (wirtschaftliche Nutzung) da coisa: assim, ainda que alguém não tenha o imóvel imediatamente sob seu poder físico, será titular da Gewere sôbre êle, se, através de terceiro, auferir seus frutos naturais ou civis (daí, dizerem as fontes que é titular da Gewere sôbre o imóvel quem o tem in Nutz und Geld).

Mas, não basta a senhoria de fato sôbre a coisa para que se tenha a Gewere; é preciso ainda que, além dêsse requisito, haja outro: a afirmação de que essa senhoria corresponde a um direito real sôbre a coisa. é por isso

50. Die Bedeutung der. Gewere im deutschen Sachenrecht, p. 22 e seg.

51. Grundzüge des Deutschen Privatrechts, $3:^{\mathrm{a}}$ ed., § 28, p. 164. 
que as fontes salientam que, se o proprietário de um imóvel o entrega a outrem para que êste simplesmente o administre, o titular da Gewere não passa a ser o administrador, mas continua a ser o proprietário. Explica-se: se é certo que o administrador exerce a senhoria de fato sôbre o imóvel, também é certo que êle — por ser meramente administrador - não afirma que essa senhoria corresponde a um direito real próprio sôbre a coisa.

Ora, a senhoria de fato sôbre a coisa e a afirmação de que ela corresponde a um direito real fazem com que se presuma que quem tem a Gewere sôbre a coisa seja titular de direito real sôbre ela. A Gewere gera, assim, a presunção da existência do direito real que ela exterioriza. E é por causa dessa presunção, e não - como ocorre na possessio - em virtude da senhoria de fato, que a ordem jurídica protege a Gewere.

Por tudo isso, H. MrTteis ${ }^{52}$, procurando estabelecer a natureza jurídica da Gewere, acentua que ela não é sòmente um fato, mas também um direito: o direito provisório ao exercício de um direito real presumido (das vorläufige Recht zur Ausübung eines vermuteten dinglichen Rechtes).

Não é, portanto, de estranhar a observação - ainda no século passado, e em época anterior aos estudos de GiERKI e de Huber - de Delbrücir ${ }^{53}$ de que a Gewere trazia em si algo de místico que parecia escapar à nossa lógica juridica.

3. Espécies de Gewere. - A mais exaustiva - que conhecemos - das classificações das espécies de Gewere. é devida a GIERKE ${ }^{54}$.

52. Deutsches Privatrecht, 3. ${ }^{\mathrm{a}}$ ed., p. 74.

53. Cfe. Sokolowski, Die Philosophie im Privatrecht, II, p. 429, nota 436 .

54. Deutsches Privatrecht, II (Sachenrecht), § 113, III, p. 190 e seg. 
Segundo Gierke, a Gewere, consoante diferentes critérios, pode assim classificar-se:

I) quanto ao fundamento a que se prende a relação de senhoria reconhecida como Gewere:

a) leibliche (hebbende ou brukende) Gewere;

b) ideelle Gewere (que AlbRecht denomina juristische Gewere; e BrunNer, unkörperliche Gewere) ${ }^{55}$;

c) rechte Gewere (também designada por LeHMANN-STOBBE como qualifizirte $\mathrm{Ge}$ were);

II) quanto à esfera jurídica dentro da qual a Gewere goza de reconhecimento e de proleção:
a) Lehengewere;
b) Dienstgewere; e
c) hofrechtlichegewere

III) quanto ao conteúdo da Gewere que se manifesta na senhoria sôbre a coisa:
a) Eigengewere (ou Obergewere); e
b) beschränkte Gewere (ou Untergewere);

IV) ao lado da gegenwärtige Gewere, há:

a) ruhende Gewere; $\mathrm{e}$

b) anwartschaftliche Gewere;

V) quanto ao objeto sôbre o qual incide a Gewere:

a) Gewere an körperlichen Sachen; e

b) Gewere an unkörperlichen Sachen; e

55. Cfe. GIERke, Deutsches Privatrecht, II (Sachenrecht), § 113, p. 193 , nota 29 . 
VI) quanto ao titular da Gewere:

a) Sondergewere; $\mathrm{e}$

b) gemeinschaftliche Gewere.

Passemos à análise sumária dessas espécies de Gewere.

É titular da leibliche Gewere (a que as fontes aludem com as expressões hebbende Gewere e brukende Gewere) quem, além de ter senhoria de fato sôbre a coisa, afirma que aquela corresponde a um direito real sôbre esta. Com relação à senhoria de fato, é preciso, porém, distinguir: se se trata de coisa móvel, a senhoria de fato se traduz na detenção material dela (ou pelo titular da Gewere, ou por um seu administrador); se se trata de coisa imóvel, a senhoria de fato se manifesta na utilização econômica (pelo titular da Gewere ou por seu administrador) do imóvel, através da percepção de seus frutos naturais ou civis. Assim, como acentua GIERKE ${ }^{56}$, na leibliche Gewere sôbre coisa móvel é preciso ter (haben) a coisa, enquanto que na leibliche Gewere sôbre coisa imóvel basta usar (brauchen).

À leibliche Gewere, que é a Gewere de fato, se contrapõe a ideelle Gewere (juristische Gewere, ou unkörperliche Geuere), que é a Gewere ideal. Essa contraposição corresponde à que se encontra nas fontes francêsas sob as denominações saisine de fait e saisine de droit.

Já a ideele (juristische ou unkörperliche) Gewere é aquela que existe independentemente de haver senhoria de fato sôbre a coisa. Ela, que se prende ao princípio da publicidade que domina todo o direito imobiliário germânico, não se aplica às coisas móveis, exceto se estas são pertenças de imóvel ou partes constitutivas de um patrimônio considerado no seu todo. A ideelle Gewere ocorre nas seguintes hipóteses:

56. Deutsches, Privatrecht, II (Sachenrecht), § 113, p. 191. 
a) o herdeiro, ainda que não tenha senhoria de fato sôbre a herança, se torna, no momento da morte do de cuius, titular da ideelle Gewere sôbre ela (o que se traduz no brocardo Le mort saisit le vif, ou, em alemão, Der Tote erbt den Lebendigen $)^{57}$;

b) quem adquire de outrem um imóvel, mediante a Auflassung ${ }^{58}$, se torna imediatamente titular da Gewere sôbre êle, ainda que não tenha obtido, de pronto, a senhoria de fato sôbre êsse imóvel;

c) aquêle que foi expulso de um imóvel por outrem, em face dêste, durante ano e dia, é considerado como se se mantivesse na Gewere do imóvel; e

d) a pessoa a quem um imóvel foi adjudicado por sentença adquire a Gewere antes mesmo de ter "senhoria de fato sôbre o imóvel.

A ideelle Gewere, porém, sòmente tem eficácia relativa, pois seu titular apenas pode invocá-la contra o esbulhador da Gewere, ou contra o alienante, ou contra aquêle que, não sendo herdeiro, se apossou da herança, ou, finalmente, contra o que foi desapossado do imóvel por sentença judicial.

Com relação à rechte (ou qualifizirte) Gewere, ela ocorre quando alguém, por mais de ano e dia, pública e

57. Sôbre êsses brocardos, vide a explicação de HEILFrom, Deutsche Rechtsgeschichte, $\S 41$, p. 346 , nota 1 da p. 345 .

58. A Auflassung é o ato solene pelo qual o alienante renuncia efetivamente a posse do imóvel. Sôbre a Auflassung, vide Sонм, Zur Geschichte der Auflassung, in Festgabe zum Doctor - Jubiläum des Herrn Geheimen Justizrathes Professors Dr. Heinrich Thöl, Strassburg, 1879 , p. 81 e seg. 
pacificamente, é titular de Gewere sôbre imóvel ou direito imobiliário ${ }^{59}$.

Surgida a rechte Gewere, seu titular passava a poder excluir pretensão dè terceiro sôbre a coisa ou sôbre direito imobiliário, a qual, se levada a Juízo antes de decorrido o prazo de ano e dia, seria acolhida (assim, por exemplo, aquêle que fôra expulso de um imóvel conservava a ideelle Gewere, e podia recuperá-lo judicialmente dentro de ano e dia; não, porém, depois de esgotado êsse lapso de tempo, porque seu adversário passava a ter a rechte Gewere).

Portanto, a posição jurídica do titular da Gewere se fortalece quando esta se transforma em rechte Gewere, que - como salienta SToBre ${ }^{62}$-, embora não se confunda com a usucapio, tem, no direito germânico medieval, a mesma importância de que desfrutava o usucapião no direito romano ${ }^{63}$.

59. A propósito da rechtc. Gewere, vide BuUntschu, Deutsche Privatrecht, 3. ${ }^{\mathrm{a}}$ ed. (besorgt von Dr. Felix Dahn), München, 1864, $\S 62$, p. 181 e seg.

60. Cfe. Stobbe-Lehmann, Handbuch des Deutschen Privatrechts, Zweiter Band, erster halbband, 3. ${ }^{\text {a }}$ ed., $§ ~ 87$, p. 217 e seg.

61. Embora EICHHORN (Einleitung in das deutsche Privatrecht mit Einschluss des Lehenrechts, $2 .{ }^{2}$ ed., Göttingen, 1825, § 170, p. 445) afirme que

"bei beweglichen Sachen war daher eine rechte Gewere nicht möglich",

os autores posteriores a êle reconhecem (vide indicação de fontes em STовве, Handbuch des Deutschen Privatrechts, $2 .^{a}$ ed., II, § 74, p. 24, nota $\left.1 .^{a}\right)$. que, excepcionalmente, se estendeu a rechte Gewere a coisas móveis.

62. Handbuch des Deutschen Privatrechts, II, 2. ${ }^{\mathrm{a}}$ ed., § 74, p. 29.

63. Para demonstrar-se que a rechte Gqwere. não se confunde com a usucapio, basta salientar que na rechte Gewere não há, como na usucapio, a transformação de um fato em um direito, mas, sim, a transformação de posse ou de aquisição de direito sujeitas à contes- 
Quanto à esfera juridica dentro da qual a Gewere goza de reconhecimento e de proteção, temos que distinguir a landrechtliche Gewere, a Lehengewere, a Dienstgewere e a hofrechtliche Gewere.

A princípio, como o Landrecht (direito territorial) não reconhecia o Lehenrecht (direito feudal), o Dientsrecht (direito dos vassalos) e o Hofrecht (ius curiae ou ius curtis) ${ }^{64}$, a Gewere sôbre as terras dadas em precarium (Leihe) ${ }^{65}$ era atribuída, segundo o Landrecht, ao senhor, enquanto que, consoante o Lehenrecht, o Dienstrecht e o Hofrecht, tinham sôbre elas a Gewere o vassalo livre, o vassalo não livre e o camponês.

Mais tarde, no tempo das compilações de direito (Rechtsbücher), passando o Lehenrecht, o Dienstrecht e o Hofrecht a ser reconhecidos pelo Landrecht, o mesmo ocorreu, em conseqüência, com a Lehengewere, a Dienstgewere $\mathrm{e}$ a hofrechtliche Gewere como unvollständige

tação em posse ou aquisição de direito incontestáveis. Vide, a propósito, Sтовве, Handbuch des Deutschen Privatrechts, II, $2 .^{\mathrm{a}}$ d., $\S 74$, p. 29 .

64. Sôbre a conceituação do Lehenrecht, do Dienstrecht e do Hofrecht, vide, entre outros, HÜBNER, Grandzüge des Deutschen Privatrechts, 3. ${ }^{\mathrm{a}}$ ed., $\S 1$, p. 3 ; e EICHHORN, Einleitung in das deutsche Privatrecht mit Einschluss des Lehenrechts, p. 8 e seg.

65. Com referência à tradução da palavra Leihe, são oportunas estas observações de Alvarez LoPEs (p. 32, nota 2, de sua tradução da História do direito germânico de BRUNNER — v. SCHWERIN) :

"La acepción medieval de la palabra leihe encuentra difícil equivalencia técnica en castellano. . . . . . . .

El sentido de aquele término, en las fuentes jurídicas alemanas contemporáneas (C.c. $\S 598$, leihe $=$ comodato), no tiene ya la holgura primitiva. Sobre la base de la amplitud terminológica de las fuentes latinas francas (BRUNNER, DRG. $I^{2}$, 304) y de las observaciones de HUEBNER, Gundzuege 5 , $\S 45$, se traducirá simplesmente por precarium, sobreentiénda-se iuris germanici”. 
(incompletas) Gewere, persistindo sôbre as terras dadas em precarium a Gewere do senhor.

E certo, porém, que há autores - assim Heusler ${ }^{66}$, LEHMANN $^{67}$ e HubeR $^{68}$ - que entendem (no que são combatidos por GIERKE ${ }^{69}$ ) que, nesse segundo período, o senhor perdia totalmente a Gewere sôbre a terra dada em precarium.

Com referência à distinção entre a Eigengewere (Gewere plena) e a beschränkte Gewere (Gewere limitada) também denominadas, respectivamente, Obergewere e Untergewere —, é de acentuar-se que aquela ocorre quando há a afirmação de direito de propriedade sôbre a coisa, enquanto que esta, quando, sôbre a coisa, se exterioriza um direito que propicia ao titular utilização limitada da coisa (assim, um direito real limitado, o direito do vassalo sôbre a terra dada em precarium, o direito do tutor sôbre os bens do tutela'do) ${ }^{70}$.

Essas duas categorias, porém, só são aceitas pelos jurisconsultos que entendem que, no direito germânico medieval, se admitia a pluralidade de Gewere sôbre uma coisa - assim, por exemplo, na locação, o locador teria sôbre a coisa a Eigengewere (ou Obergewere), e o locatário a beschränkte Gewere (ou Untergewere), e isso

66. Institutionen des Deutschen Privatrechts, zweiter Band, § 82, p. 28 .

67. Handbuch des deutschen Privatrechts von Отто Sтовве neu bearbeitet von H. O. LEHMANN, zweiter Band (erster halband), 3. ${ }^{\mathrm{a}}$ ed., $\S 85$, p. 199.

68. Die Bedeutung der Gewere im Deutschen Sachenrecht, p. 30.

69. Deutsche Privatrecht, zweiter Band (Sachenrecht), § 113, p. 199, nota 50 .

70. Note-se que se dá a denominação de gemene (ou blote) Gewere à Gewere sem se levar em consideração o título jurídico em que ela se baseia (vide, a propósito, GIERKE, Deutsche Privatrecht, zweiter Band - § 133, p. 199, nota 51). 
porque aquêle tira dela utilização mediata, e êste, imediata ${ }^{11}$.

Há autores - e do porte de Heusler ${ }^{72}$ - que negam fôsse possível, no direito germânico medieval, essa pluralidade. Alguns, no entanto, como LEHMANN ${ }^{73}$, embora rejeitańdo também essa pluralidade ${ }^{74}$, admitem que, nas fontes, excepcionalmente, há hipóteses em que ocorre a pluralidade de Gewere sôbre uma coisa; assim, por exemplo, se o vassalo transmite a terceiro a Gewere de que dispõe, não perde êle a Gewere em face do senhor feudal. Mas nesses casos - observa LeHMANN ${ }^{75}$ - apenas uma pessoa tem a absolute Gewere (Gewere absoluta, isto é, a que se faz valer contra qualquer um); a outra (ou outras) sòmente é titular da relative Gewere (Gewere relativa, ou seja, a que vale apenas em face de determinada pessoa assim, no exemplo anterior, o vassalo, que transferiu a absolute Gewere a terceiro, conserva apenas uma relative Gewere em face do senhor feudal). Para Lehmann,

71. Nesse sentido, entre outros, GIERKE, Deutsches Privatrecht, zweiter Band (Sachenrecht), § 113, p. 199 e seg.; e MITTEIS, Deutsches Privatrecht, 3. ${ }^{\mathrm{a}}$ ed., p. 74.

72. Institutionen des Deutschen Privatrechts, zweiter Band, § 82, p. 25 e seg.

73. Handbuch des Deutschen Privatrechts von Отто Sтовве neu bearbeitet von $\mathrm{H}$. O. LEHMANN, zweiter Band (erster halbband), 3. ${ }^{\mathrm{a}}$ ed., § 85, p. 199 e seg.

74. São de LeHMANN (ob. cit. na nota anterior, p. 199) estas palavras:

"Eine mehrfache Gewere giebt es nicht. Es hat nicht etwa einer (z. B. Zinsherr, Lehnsherr) eine Ober-Gewere, ein anderer (Zinsmann, Vasall) eine Unter-Gewere..."

75. Ob. cit., p. 199. 
sòmente a absolute Gewere é a verdadeira Gewere, pois a relative Gewere se baseia tão só em uma ficção jurídica ${ }^{76}$.

Note-se, enfim, que, admitida essa classificação (Obergewere e Untergewere), se divisaria, aí, a origem germânica da distinção, acolhida no Bürgerliches Gesetzbuch, entre a posse imediata (ou direta) e a posse mediata (ou indireta).

Além da gegenwärtige Gewere (Gewere atual), GIERKE" distingue a ruhende Gewere (Gewere paralizada) e a anwartschaftliche Gewere (Gewere em formação).

A ruhende Gewere, consoante Mitreis ${ }^{78}$, é a que existe sem que haja utilização da coisa cognoscível externamente; GIERKE $^{79}$, porém, prefere caracterizá-la salientando que a ruhende Gewere "corresponde a um direito real atual reconhecido como existente, que, no momento, não proporciona nenhum gôzo, mediato ou imediato, da coisa". Assim, tem a ruhende Gewere o titular da Gewere sôbre uma coisa que entrega esta a seu credor, a título de garantia real (penhor); nesse caso, segundo vários autores (como Gierke e MitTeis) ${ }^{80}$, a Gewere não se perde, mas fica paralizada. É certo, porém, que há jưristas - como

76. Handbuch des Deutschen Privatrechts von Oтто STовве neu bearbeiteit von H. O. LEHMANN, zweiter Band (erster halbband), 3. ${ }^{\mathrm{a}}$ ed., $\S 85$, p. 204 , onde se lê:

"Wahre Gewere ist nur die absolute Gewere; sie ist stets eine einheitliche. Die daneben vorkommende relative Gewere beruht auf Rechtsfiktion".

77 Deutsches Privatrecht, zweiter Band (Sachenrecht), § 113, p. 200 e seg.

78. Deutsches Privatrecht, $3 .^{\mathrm{a}}$ ed., p. 75.

79. Deutsches Privatrecht, zweiter Band (Sachenrecht), § 113, p. 200 e 201.

80. Vide passagens citadas nas notas 78 e 79. 
HUber $^{81}$ e STOBBE $^{82}$ - que negam a existência da ruhende Gewere, por entenderem que, em hipóteses como essa, a pessoa que entregou a terceiro a coisa perde a Gewere sôbre ela.

Já a anwartschaftliche Gewere (Gewere em formação) é a que corresponde a um direito real que poderá surgir, eventualmente, no futuro — por exemplo: a que ocorre em favor daquele a quem se transfere, sob condição suspensiva, direito de propriedade sôbre uma coisa.

Quanto ao objeto sôbre que incide a Gewere, pode ser êle - segundo GIERKE ${ }^{83}$ - uma coisa corpórea ou um direito; daí, a distinção entre a Gewere an körperlichen Sachen e a Gewere an unkörperlichen Sachen.

Se, com relação à Gewere an körperlichen Sachen, não há divergência entre os autores (que a admitem com referência a móveis e a imóveis), o mesmo não ocorre quanto a Gewere an unkörperlichen Sachen. Com efeito, autores mais antigos - como Bruns ${ }^{84}$ e, em parte, BESELER ${ }^{85}$.

81. Die Bedeutung der Gewere im Deutschen Sachenrecht, p. 27.

82. Salienta STоввE, no Handbuch des Deutschen Privatrechts, zweiter Band, $2 .^{\mathrm{a}}$ ed., $\S 7,2$, p. 15 :

"Andererseits ist die Gewere nicht mit dem dinglichen Recht an sich verbunden: der Eigenthümer hat keine Gewere, so lange der Pfandgläubiger das Grundstück in Satzung, der Leibzüchter als Leibzucht besitzt.."

E conclui, linhas abaixo: tung".

"Es giebt keine eventuelle, keine Gewere zur Anwar-

83. Deutsches Privatrecht, zweiter Band (Sachenrecht), § 113, p. 201 e seg.

84. Das Recht des Besitzes im Mittelalter und in der Gegenwart, p. 331 .

85. System des gemeinen deutschen Privatrechts, erste Abtheilung, $\S 79$, p. 315 e seg., onde BESELER salienta que era assim primitivamente, mas, depois, 
- entendiam que o direito germânico medieval não conheceu uma Gewere am Rechte como instituto independente (ao contrário do que acontecia no direito romano com a possessio iuris, que se baseava no princípio usus iuris pro possessione $)^{86}$, mas a ela chegava de modo indireto, pois, podendo a Gewere sôbre coisa corpórea exteriorizar qualquer direito que se exercesse com relação a esta, quem era titular da Gewere sôbre a coisa objeto do direito exteriorizado pela Gewere, dispunha, em última análise, da Gewere sôbre êsse direito. Procurando esclarecer essa tese, BOURCART $^{87}$ - que segue de perto Bruns - salienta:

"... on ne connaissait pas de "Gewere am Rechte" indépendante et distincte. Mais la Gewere an der Sache comprenait en elle tous les droits qu'une personne possédait sur la chose soumise à la Gewere; et ainsi le droit faisait aussi l'objet d'une Gewere, mais non pas d'une Gewere séparée: on avait la Gewere am Rechte, parce qu'on avait la Gewere de la chose objet du droit. Par exemple le droit d'un évèque sur une communauté, le droit d'un seigneur sur un village étaient compris dans la Gewere de l'évèque sur la communauté, du seigneur sur le village"s8.

“... die selbständige Entwickelung deutscher Rechtsinstitute führte doch dahin, eine Gewere an dem Rechte auch ohne die unmittelbare Herrschaft über die Sache gelten zu lassen".

86. A propósito, vide Bruns, Das Recht des Besitzes im Mittelalter und in der Gegenwart, p. 331.

87. Étude Historique et Pratique sur les Actions Possessoires, p. 159 .

88. BRUns, Das Recht des Besitzes im Mittelalter und in der Gegenwart, p. 331, assim se explica:

"Indessen kann man diese Gewere des Zinsrechtes doch der Römischen iuris possessio keineswegs gleichstellen. Das Princip ist hier nicht, dass der usus iuris pro prossessione 
Ainda segundo êsses autores, foi o direito canônico que, por analogia à possessio iuris do direito romano, distinguiu, como institutos independentes, a Gewere an der Sache e a Gewere am Rechte, sem, no entanto, atribuir características diversas a ambas, que foram, aliás, assimiladas à possessio rei e à possessio iuris.

Essa, porém, não é a opinião dos escritores mais modernos que se ocuparam da matéria. Para êstes - assim, GIERKE $^{89}$ e LEHMANN ${ }^{90}$-, as fontes germânicas medievais indicam a existência da Gewere am Rechte, como instituto independente, e Gewere que pode ter por objeto um círculo bem mais amplo de direito do que o dos poucos direitos reais que, segundo o direito romano, eram susceptíveis de possessio iuris. Com efeito, como salienta Brun$\mathrm{NER}^{91}$, podiam ser objeto de Gewere os direitos que admitiam exercício duradouro:

"Gewere war nicht bloss an körperlichen Sachen, sondern ausch an Rechten möglich, die eine dauernde Ausübung zuliessen"92.

sei, sondern die Gewere am Zinse beruht darauf, das der Zinsherr eine Gewere am Zinsgute selbst hat, die ihm das Recht giebt, den Zinsmann, wenn er nicht sahlt, auszupfänden, oder sich sogar des: Zinsgutes zu eigen zu interwinden. ......

Stets aber ist die Gewere am Zinse mit dieser Gewere an dem Gute so innig verbunden, dass von einem eigentlichen Besitze des Rechtes als solchen kaum die Rede sein kann" p. 202.

89. Deutsches Privatrecht, zweiter Band (Sachenrecht), § 113,

90. Handbuch des Deutschen Privatrechts von Отто Sтовве neu bearbeitet von H. O. LEHMANN, zweiter Band (erster halbband), 3. ${ }^{\mathrm{a}}$ ed., § 85, p. 204.

91. Quellen und Geschichte des deutschen Rechts, in Enzyklopädie der Rechtswissenschaft de HOLTZENDORFF, erster Band, 7.a ed., p. 133.

92. A propósito, vide também Lehman, Handbuch des Deutschen Privatrechts von Отто STOBвE neu bearbeitet von $\mathrm{H}$. O. LEHMANN, zweiter Band (erster halbband), 3.a ed., § 85, p. 205. 
Finalmente, a Gewere, quanto ao seu titular, se distingue em Sondergewere e em gemeinschaftliche Gewere (isto é, em Gewere singular e em Gewere em comum, conforme seja exercida, respectivamente, por uma só pessoa, ou por várias conjuntamente).

Por outro lado, quanto à gemeinschaftliche Gewere, esclarece GIERKE ${ }^{93}$ que à antiga Genossenschaft (corporação do direito germânico) corresponde uma genossenschaftliche Gesamtgewere, e à Gemeinschaft zur gesamten Hand (comunidade em mão comum) uma Gewere zu gesamter Hand.

4. Aquisição e perda da Gewere. - A aquisição da Gewere, como salienta LEHMANN ${ }^{94}$ - a quem seguimos na exposição abaixo -, ou é originária, ou é derivada.

Estudando ambas essas espécies de aquisição da $\mathrm{Ge}$ were, LEHMANN distingue os imóveis dos móveis.

Com relação aos imóveis, ocorre a aquisição derivada da Gewere quando se verifica:

a) a transferência para outrem - a princípio, através da reale Investitur; depois, mesmo da symbolische Investitur ${ }^{95}$ — do imóvel, realizada pelo até então titular da Gewere; ou

93. Deutsches Privatrecht, zweiter Band (Sachenrecht), § 113, p. 203.

94. Handbuch des Deutschen Privatrechts von Отто STоввE neu bearbeitet von H. O. LEHMANN, zweiter Band (erster halbband), 3. ${ }^{\mathrm{a}}$ ed., $\$ 86$, p. 206 e seg.

95. Como salienta SoHM (Zur Geschichte der Auflassung, in Festgabe zum Doctor-Jubiläum des Herrn Geheimen Justizrathes Professors Dr. Heinrich Thöl, p. 85 e seg.), há duas espécies de Investitur: a reale Investitur e a symbolische Investitur.

Quanto à reale Investitur, escreve SоHм (ob. cit., p. 85) :

"Die reale Investitur ist die feierliche Besitzübertragung des Grundstücks, welche auf dem Grundstück selber vor Zeugen und unter bestimmten Solennitäten vollzogen wird. 

b) a adjudicação; ou
c) a transmissão hereditária.

$\mathrm{Na}$ aquisição derivada, não só ela ocorre ipso iure, mas também, através dela, sempre sè adquire sôbre o imóvel a rechte Gewere.

Já a aquisição originária da Gewere sôbre imóvel se dá quando alguém, sem ser mediante o emprêgo de um dos meios de aquisição derivada, obtem a posse útil (Nutzbesitz) ${ }^{96}$ do imóvel, com a intenção de tê-lo para si $^{97}$. Através da aquisição originária, não se adquire a rechte Gewere sôbre a coisa imóvel, o que só se vai verificar se a Gewere perdurar durante ano e dia sem ataque.

Die Solennitäten der realen Investitur sin zweierlei: der solenne Apprehensionsakt und der solenne Auflassungsakt".

Já com relação à symbolische Investitur, esclarece BRUNNER (Quellen und Geschichte des deutschen Rechts, in Enzyklopädie der Rechtswissenschaft de HOLTZENDORFF, I, $7 .^{\mathrm{a}}$ ed., § 46, p. 133):

"Doch bilteten sich achon in frändischer Zeit Formen einer unkörperlichen (symbolischen) Vestitur aus, die als konsensuale Besitzübertragung und Besitzräumung mit Übergabe bestimmter Symbole ausserhalb des Gundstückes stattfand"

96. Nutzbesitz (posse útil), porque, como salientamos no n. ${ }^{\circ} 2$, “na Gewere sôbre coisa imóvel há senhoria de fato desde que exista utilização econômica (wirtschftliche Nutzung) da coisa: assim, ainda que alguém não tenha o imóvel imediatamente sob seu poder físico, será titular da Gewere sôbre êle, se, através de terceiro, auferir seus frutos naturais ou civis (daí, dizerem as fontes que é titular da Gewere sôbre o imóvel quem o tem in Nutz und Geld)".

97. $\mathrm{E}$ animus rem sibi habendi. Sôbre o animus na Gewere, vide, entre outros, Sтовве, Handbuch des Deutschen Privatrechts, zweiter Band, 2. ${ }^{\mathrm{a}}$ ed., $\S 72$, p. 15; KOHLER, Pfandrechtliche Forschungen, Jena, 1882, p. 78 e seg.; e Sонм, Zur Geschichte der Auflassung, in Festgabe zum Doctor-Jubiläum des Herrn Geheimen Justizrathes Professors Dr. Heinrich Thöl, p. 107 e seg. 
Quanto aos móveis, LeHMaNN ${ }^{98}$ julga conveniente distinguír os modos de aquisição que fazem surgir, ipso iure, a Gewere contra todos, daqueles pelos quais a Gewere só se torna oponível ao alienante depois de decorridos três dias (sessio tridu'ana) ${ }^{99}$.

A Gewere se adquire ipso iure (sem ser necessário mesmo a tomada efetiva de posse), e é desde logo oponível contra todos, quando há:

a) transmissão hereditária (o herdeiro se torna titular da Gewere sôbre as coisas móveis que se encontravam sob a Gewere do de cuius);

b) imissão judicial na posse da coisa móvel; e

c) a adjudicação, pelo juiz, de um imóvel, hipótese em quє, além de nascer, para o adjudicante, a Gewere sôbre o imóvel, surge também para êle a Gewere sôbre as coisas móveis que se encontram no imóvel e que não estão sob $G e$ were alheia.

Já nos dois casos que se seguem, além de ser necessária a tomada efetiva de posse, a Gewere sòmente passa a ser oponivel ao alienante depois de transcorridos três dias. Isso se dá quando a Gewere sôbre coisa móvel surge:

a) através da tradição da coisa; e

b) através da tomada de posse dolosa da coisa.

A Gewere se extingue, quer com relação aos imóveis, quer com referência às coisas móveis, quando se perde o

98. Handbuch des Deutschen Privatrechts von Otto Stobbe neu bearbeitet von H. O. LEHMANN, zweiter Band (erster halbband), $3 .^{\text {a }}$ ed., $\S 86$, p. 208 e seg.

99. A propósito, vide GIERke, Deutsches Privatrecht, zweiter Band (Sachenrecht), § 112, p. 196, nota 39; e JobBÉ-DuvaL, Etude Historique sur la Revendication des Meubles en Droit Français, Paris, 1880 , p. 25 , nota 2 . 
poder de fato sôbre a coisa, e outrem o adquire, tornandose, assim, titular da Gewere sôbre ela. Isso não se verifica, porém, nas hipóteses em que ocorre a ideelle Gewere (vide . $^{\circ} 3$ ), ou - para os autores, como LehmanN, que admitem a distinção entre a absolute Gewere e a relative Gewere - a relative Gewere (embora, neste último caso, se extinga a absolute Gewere).

5. Os três efeitos da Gewere. - Os autores, por via de regra, concordam em que a Gewere produz três espécies de efeitos:

a) o efeito defensivo (denominado por Huber: Defensivwirkung; por GIERKE: Wirkung der Rechtsverteidigung; e por ConRad: Verteidigungswirkung $)^{100}$;

b) o efeito ofensivo (denominado por HUBER: Offensivwirkung; e por Grenke: Wirkung der Rechtsverwirklichung) ${ }^{101}$; e

c) o efeito translativo (denominado por HUBER: Translativwirkung; por GIERKE: Wirkung der Rechtsübertragung; e por CoNRAD: Uebertragungswirkung) ${ }^{102}$.

Analisemo-los, separadamente.

\section{A) - o Efeito Defensivo.}

Graças ao ef eito defensivo da Gewere, pode seu titular - ainda que ela tenha sido adquirida através de ato

100. HUBER, Die. Bedeutung der Gewere im Deutschen Sachenrecht, p. 19; GIERKE, Deutsches Privatrecht, zweiter Band (Sachenrecht), $\S 113$, p. 203; e CONRAD, Deutsche Rechtsgeschichte, Band I (Frïhzeit und mittelalter), 1954, p. 567.

101. HUBER, ob cit., p. 19; GIERKe, ob. cit., p. 204.

102. HUBer, ob. cit., p. 21; GIERKE, ob. cit., p. 204; e CONRAD, ob. cit., p. 567 . 
ilícito (assim, por exemplo, mediante roubo) $)^{103}-\mathrm{de}-$ fendê-la :
a) com o emprêgo da fôrça, se alguém pretender despojá-la dela por ataque extrajudicial; ou
b) na própria ação judicial que outrem lhe mova para retirar-lhe a Gewere.

A defesa pela própria fôrça física se explica pelo fato de que as fontes germânicas medievais acentuam que o titular da Gevere não pode ser privado dela senão através de sentença judicial (mit Urteil und Recht).

Por outro lado, o direito presumido que se exterioriza através da Gewere pode ser posto em dúvida, sendo ela, portanto, suceptível de ser atacada judicialmente. Nesse caso, seu titular goza de posição processual favorável, no que diz respeito à preferência no tocante à prova: a Gewere possibilita a seu titular fazer prova em primeiro lugar, e isso, no processo germânico, é vantagem, pois, aí, ao contrário do que ocorre no direito romano e no direito moderno, a prova não é onus, mas, sim, direito da parte. Por isso, salienta BourcarT ${ }^{104}$ :

"Et voici en quoi la situation du possesseur est plus avantageuse; sa possession lui donne le droit de faire la preuve le premier. En effet, au rebours des idées romaines et de nos idées modernes, la preuve constitue un droit et non pas un fardeau, et dès lors celui qui a la priorité du droit à la preuve a l'avantage sur son adversaire; il a l'avantage de celui qui tire le premier dans un duel"105.

103. Cfe. GIERKE, Grundzïge des deutschen Privatrechts, in Enzyklopädie der Rechtswissenschaft de HOLTZENDORFF, erster Band, p. 226.

104. Étude historique et pratique sur les actions possessoires, p. 168. 
Ł certo, porém, que entre os autores não há concordância sôbre o motivo por que se atribui ao réu essa vantagem. De acôrdo com a doutrina dominante, isso decorre da simples condição de réu. Segundo alguns autores modernos, ela resulta da circunstância de que o réu, como titular da Gewere, está em condições de saber melhor como a adquiriu ${ }^{106}$.

\section{B) - o Efeito Ofensivo.}

Quanto ao efeito ofensivo, é preciso distinguir a $G e$ were sôbre coisa imóvel da Gewere sôbre coisa móvel.

$\mathrm{Em}$ se tratando de imóveis, o efeito ofensivo da $\mathrm{Ge}$ were ocorre quando se configuram a ideelle Gewere, a ruhende Gewere, a anwartschaftliche Gewere e a Obergewere (ou Eigengewere). Em tôdas essas hipóteses, o titular da Gewere podia recuperar a posse útil da coisa imóvel (leibliche Gewere) através de ação judicial contra aquêle que tivesse sôbre o imóvel a leibliche Gewere ${ }^{107}$. Assim, por exemplo, num dos casos de ideelle Gewere, o despojado de um imóvel podia tentar recuperá-lo com o

105. A propósito, escreve Bruns (Das Recht des Besitzes im Mittelalter und in der Gegenwart, p. 288 e seg., nota 1):

"Dabei muss man sich erinnern, dass im Germanischen Rechte die Parteien ihre Behauptungen in der Regel nicht eigentlich beweisen, sondern nur entweder sie beschwören, allein oder mit Eideshelfern, oder ein Gottesurtheil, namentlich Zweikampf, darüber entscheiden lassen; dass daher, namentlich in erstern Falle, der Beweis keine Last, sondern ein Recht ist, und der Vortheil des Beklagten im Processe (namentlich auch des Besitzers bei Sachklagen) nicht in der Freiheit vom Beweise, sondern umgekehrt in dem Rechte zum ersten Beweise besteht".

106. A propósito, vide BRUNNER-ScwerIN, Historia del Derecho Germánico, trad. ÁLVAREZ LóPES, § 46, p. 196, nota, devida ao tradutor.

107. Sôbre a ação de que trata o texto, vide BETHMANN-HoLlWEG, Der Civilprozess des gemeinen Rechts in geschichtlicher Entwicklung, IV, $\S 24$, p. 53 e seg. 
emprêgo da fôrça; não o conseguindo (e ainda mesmo que não o tentasse), dispunha êle de ação judicial contra o esbulhador para restabelecer sua leibliche Gewere. Tambem na hipótese de ruhende Gewere - e o exemplo é de HüBNER ${ }^{108}$-, se alguém arrendasse um imóvel a um lavrador, por tôda a vida dêste, e se o lavrador falecesse e seu herdeiro se recusasse a restituir o imóvel, quem arrendara (e era, portanto, o titular da ruhende Gewere) podia intentar-lhe ação para obter o restabelecimento de sua leibliche Gewere.

Já com relação às coisas móveis o panorama era diverso. Desde os tempos mais remotos, era preciso distinguir a privação voluntária da privação involuntária da Gewere, embora, em ambas as hipóteses, a pessoa despojada da Gewere a perdesse, por não mais deter efetivamente a coisa.

Quando ocorria privação voluntária da Gewere (assim, se a coisa móvel tivesse sido entregue a um depositário ou a um comodatário), a pessoa que dela fôra voluntàriamente privada - se a outra a quem confiara a coisa se negasse a restituí-la - sòmente dispunha de ação pessoal contra esta, para obter a restituição do móvel, ou, se isso não fôsse mais possível, indenização correspondente a seu valor. Dessa forma, se a pessoa, a quem a Gewere tinha sido confiada, a transferisse a terceiro, contra êste (ainda que estivesse de má fé) o privado da Gewere não tinha ação judicial para obter a restituição da coisa, mas apenas ação pessoal contrá aquêle a quem êle confiara a Gewere, para conseguir indenização. Vigorava, a propósito, o brocardo Hand muss Hand wahren (a mão deve guardar a mão $\left.{ }^{109}\right)$, ou - como salienta Bethmann-Hollweg ${ }^{110}-W o$

108. Grundzüge des Deutschen Privatrechts, 3. ${ }^{\mathrm{a}}$ ed., $\S 28$, p. 176.

109. Sôbre êsse princípio, vide G. BESELER, Hand wahre Hand, in Studi di Storia e Diritto in onore di Enrico Besta per il XL anno del suo insegnamento, I, Milano, 1939, p. 201 e seg.

110. Der Civilprozess des gemeinen Rechts in geschichtlicher Entwicklung, IV. § 8, p. 15, nota 10. 
ich meinen Glauben gelassen habe, da muss ich ihm wieder suchen (onde eu deixei minha confiança, lá devo buscá-la de nôvo). Daí, dizer-se na Idade Média: mobilia non habent sequelam (não há faculdade de seqüela em matéria de móveis).

Se, porém, a privação da Gewere fôsse involuntária (e isso ocorria nas hipóteses de perda, furto ou roubo da coisa móvel), quem dela se vira privado contra ou sem sua vontade (mesmo que não o proprietário) dispunha - se não tivesse pilhado o ladrão em flagrante (handhafte Tat) e impedido com o emprêgo da fôrça a privação da Gewere; ou, então, se o ladrão houvesse fugido sem deixar vestígios que permitissem seguir a coisa furtada ou roubada para reavê-la (Spurfolge); ou, finalmente; se a coisa apenas fôsse encontrada depois de três dias do furto ou do roubo -- de uma das duas seguintes ações para recuperar a coisa:

a) a Anefangsklage ${ }^{111}$, que era precedida de processo extrajudicial para a localização da coisa (a Anefang, que, como perceberam de há muito Grimm e WiLdA ${ }^{112}$, apresenta acentuada analogia com a perquisitio lance licioque do direito romano ${ }^{113}$, e que, se fôsse julgada improce-

111. Sôbre a Anefangsklage, vide BETHMANN-HolLWEG, Der Civilprozess des gemeinen Rechts in geschichtlicher Entwicklung, IV, $\S 23$, p. 40 e seg.; ScHRÖDER, Lehrbuch der Deutschen Rechtsgeschichte, 4. ${ }^{\text {a }}$ ed., Leipzig, 1902, p. 376 e seg. (exposiçã̃o muito clara); HüBNER, Grundzüge des Deutschen Privatrechts, 3.a ed., § 58, p. 358 e seg.; JoBBÉ-Duval, Étude historique sur la revendication des meubles en Droit Français, p. 21 e seg.; e KARL RAUCH, Spurfolge und Anefang in ihren Wechselbeziehungen, Weimar, 1908, p. 4 e seg.

112. Cfe. JoвbÉ-Duval, Étude historique sur la revendication des meubles en Droit Français, p. 23.

113. A perquisitio lance licioque era a busca a que a vítima do furto procedia na casa do suspeito como ladrão, trajando ela, apenas, um pequeno calção que lhe cobria a parte inferior do tronco, e tendo, nas mãos, um prato, ritual antiquíssimo e que, no tempo de GAIo, já se afigurava ridículo (GAIO, Institutas, III, 193). 
dente, acarretava não só a condenação do autor a pagar multa (eine Busse), mas também, eventualmente, sua responsabilidade penal ${ }^{114}$; e

b) a schlichte Klage ${ }^{115}$, que era, como acentua Schulte ${ }^{116}$, uma ação que, sem ter havido a Anefang, se fundava na simples afirmação do autor de que o réu tinha em seu poder coisa do primeiro; demais, não havia qualquer risco para o autor se a ação fôsse julgada improcedente.

\section{C) - 0 Efeito Translativo.}

Sòmente podia transferir direito real sôbre uma coisa - quer móvel, quer imóvel - quem possuisse a Gewere sôbre ela. Assim, como acentua HuBER ${ }^{117}$, a Gewere atribui a seu titular a legitimação para transferir a terceiro o direito real que êle tem sôbre a coisa. Em outras palavras: a transmissão do direito real só se faz sob a forma de transmissão da Gewere, que, dêsse modo, é pressuposto daquela transferência ${ }^{118}$.

114. Cfe. ScHRÖDER, Lehrbuch der Deutschen Rechtsgeschichte, $4 .^{\mathrm{a}}$ ed., p. 380 .

115. Vide, a propósito, HüBNER, Grundzüge des Deutschen Privatrechts, $3 .^{\mathrm{a}}$ ed., $\S 58$, p. 361 .

116. Lehrbuch der deutschen Reichs - und Rechtsgeschichte, 4. ${ }^{\mathrm{a}}$ ed., $\S 153$, p. 488.

117. Die Bedeutung der Gewere im Deutschen Sachenrecht, p. 21.

118. Daí, dizer PLANITZ, Germanische Rechtsgeschichte, 3. ${ }^{\mathrm{a}}$ ed., Berlin, 1944, § 49, p. 215 :

"Die Uebertragung des dinglichen Rechtes war nur unter der Form der Uebertragung der Gewere wirksam". 